\title{
Necesidad de la implementación de la segunda instancia $o$ apelación en arbitraje
}

\author{
Leonardo Sempértegui Vallejo*
}

SUMARIO: 1. Origen y validez de la potestad arbitral según la legislación vigente en Ecuador. 2. ¿La naturaleza jurídica del arbitraje obliga a tener una sola instancia? 2.1. Razones que fundamentan la necesidad de segunda instancia o apelación en arbitraje. 2.2. ¿La ley ecuatoriana permite la realización de segunda instancia o apelación en arbitraje? 2.3. Aplicación de cláusulas de segunda instancia en arbitraje. 3. ¿Cómo debe incorporarse tal disposición en la cláusula estándar ecuatoriana? 4. Conclusión.

\section{Origen y validez de la potestad arbitral según la legislación vigente en Ecuador}

La potestad de administrar justicia es una de las esenciales del ejercicio del poder público ${ }^{1}$, desde el inicio del Estado Liberal. La Constitución del año 2008 del Ecuador, a pesar de que recoge de manera limitada los principios del Estado moderno, ya que su influencia es de otra naturaleza que no es materia de este artículo, considera a la administración de justicia como elemento esencial del Estado. El artículo 167 de la Constitución del Ecuador, señala:

La potestad de administrar justicia emana del pueblo y se ejerce por los órganos de la Función Judicial y por los demás órganos y funciones establecidos en la Constitución ${ }^{2}$.

\footnotetext{
* Abogado por la Universidad Católica del Ecuador, Master en Derecho por la Universidad de Texas en Austin, USA. Socio del Estudio Jurídico Sempértegui Ontaneda Abogados (Quito, Ecuador), en el que dirige la práctica de derecho administrativo y derecho energético. Consultor en materia de acceso a la justicia y elaboración normativa a nivel nacional e internacional. Catedrático universitario en Ecuador y en el extranjero. Becario Fulbright, 2008.

1. J. Perez Royo, Curso de Derecho Constitucional, Octava Edición, Marcial Pons. Madrid, 2002, p. 745.

2. Constitución del Ecuador.
} 
Precisamente por la apertura que se deriva del texto transcrito es que el arbitraje ha tenido cabida en el sistema jurídico ecuatoriano. Se ha reconocido a nivel constitucional al arbitraje, la mediación y otros sistemas alternativos de solución de controversias, a través de la disposición contenida en el artículo 190 de la Constitución, que es de carácter general y para cuya aplicación se requiere necesariamente de un mandato legal concordante ${ }^{3}$.

De lo dicho se desprende entonces con claridad que el Estado delega parte de su capacidad de administración de justicia a terceras entidades privadas (o permite que estos terceros ejecuten administración de justicia), que ejecutan el ejercicio del arbitraje, entre otras formas de solución de controversias aceptadas constitucionalmente ${ }^{4}$. Así parece describirlo el artículo 7, inciso cuarto, del Código Orgánico de la Función Judicial cuando señala que "Los árbitros ejercerán funciones jurisdiccionales, de conformidad con la Constitución y la ley"5.

Toda delegación, sin embargo, comprende no solamente la transferencia de atribuciones sino la obligación del cumplimiento de los deberes inherentes a la misma. Por ello es que consideramos que los árbitros están obligados a acatar en el ejercicio de sus funciones los principios, reglas y mandatos aplicables para los jueces, que se encuentran contenidos en la misma Constitución, pero igualmente en las normas legales tales como el Código Orgánico de la Función Judicial, así como en las normas procesales aplicables ${ }^{6}$.

3. No se pueden desconocer en todo caso las teorías que, en un contexto globalizado y de pluralismo jurídico, buscan separar el arbitraje del cobijo de un Estado o legislación en particular, sometiéndolo principalmente al gobierno de la voluntad de las partes. Ver J. PAulson, Arbitration in Three Dimensions, London School of Economics and Political Science, Law, Society and Economy Working Papers 2/2010, Law Department, 2010. Disponible en: http://ssrn.com/abstract=1536093.

4. De hecho, otros autores opinan que lo que opera en realidad es un intento de sustitución por parte del arbitraje a la función judicial, por motivos de eficiencia. Ver F. DE TrazEgniEs GRANDA, "Los Conceptos y las Cosas: Vicisitudes Peruanas de la Cláusula Compromisoria y del Compromiso Arbitral”, en El Arbitraje en el Derecho Latinoamericano y Español, Cultural Cuzco, 1989, p. 546.

5. Código Orgánico de la Función Judicial, Registro Oficial suplemento No. 544 de 9 de marzo de 2009.

6. “... si la función estructural de la justicia estatal, en el derecho privado, es la de resolver conflictos entre particulares, al permitir el mismo estado mediante la ley, que los mismos particulares designen sus jueces y éstos, mediante un procedimiento decidan un conflicto, estaremos claramente en presencia de un equivalente funcional, al papel que cumple la justicia estatal. No se trata de otra justicia. Se trata de la misma con otros actores principales (árbitros), pero con las mismas partes y el mismo conflicto a resolver, todo lo cual nos libera de tener que tomar partido, en el caso del arbitraje, por una naturaleza jurídica contractualista, jurisdiccional, mixta o ecléctica”. Á. SALCEDo FLóREZ, En torno a la naturaleza jurídica del arbitraje, Revista Análisis Internacional, Universidad de Bogotá Jorge Tadeo Lozano, No. 2, 2010, p. 154. 
Solamente como ejemplo señalo que los árbitros están absolutamente obligados a observar adecuadamente los principios de aplicación de derechos incluidos en el artículo 11 de la Constitución de la República. Muchos de ellos son directamente aplicables a los jueces, y según la lectura que se expone en este ensayo, los árbitros deben verlos como propios en los casos en que se apliquen ${ }^{7}$.

Esta última afirmación se explica por sí sola: Es indispensable para que la seguridad jurídica esté adecuadamente servida, que los árbitros ejerzan la potestad delegada constitucional de forma tal que se atienda plenamente el objetivo de la administración de justicia en sí mismo, haciendo abstracción del operador que la ejecuta. Caso contrario, esta (y cualquier otra atribución delegada) sería un ataque directo a la atención de la necesidad ciudadana de restauración del Estado de Derecho y del imperio de la ley, que es a lo que los juzgadores están llamados como tarea principal.

Más allá de la precisión y legalidad en la ejecución de la tarea arbitral para beneficio de la sociedad, existe un motivo egoísta para que los árbitros cumplan su función de manera impecable; y es que la supervivencia del arbitraje como tal se fundamente en su reputación. Como fue señalado en la introducción, la comunidad jurídica ha abrazado el arbitraje como una alternativa válida a la resolución judicial de conflictos, especialmente por su celeridad e independencia, esto a pesar de que las críticas al arbitraje no han escaseado ${ }^{8}$. Sin embargo, creo que es evidente que tales características o ventajas que ha ofrecido el arbitraje se verían oscurecidas en caso que se extienda en la misma comunidad jurídica la sensación de que se están dictando laudos errados en derecho, sea la razón que sea que motive los yerros arbitrales.

Por lo tanto, de esta sección concluimos que el arbitraje debe buscar cumplir rigurosamente su deber de administración de justicia y restablecimiento del imperio de la ley por dos motivos: uno teleológico, esto es en

7. Más adelante nos referiremos a la responsabilidad sobre error judicial que tiene el Estado, y cómo esta podría entenderse en materia arbitral.

8. Se señalan como críticas al arbitraje en general, además de la falta de apelación, la limitada actuación probatoria necesaria para ciertos casos complejos, falta de jurado, costos excesivamente altos, ventajas relativas de la parte que acude al arbitraje con frecuencia, entre otras. Ver C. DRAHOZAL, "Unfair” Arbitration Clauses, 
sí mismo garantizar a la sociedad que el estado de derecho existe; y otro pragmático, que es asegurar su propia supervivencia como medio alternativo de solución de conflictos.

\section{2. ¿La naturaleza jurídica del arbitraje obliga a tener una sola instancia?}

Para evaluar si la proposición que plantea este ensayo tiene posible aplicación, es indispensable repasar cuáles son los elementos que explican la naturaleza jurídica del arbitraje, es decir aquellos que en caso de ser modificados o eliminados transformarían el arbitraje en otro mecanismo de solución de conflictos. Una vez determinados estos, resulta sencillo saber si la apelación o segunda instancia que podría introducirse vuelve al arbitraje otra institución del derecho?.

Múltiples autores han tratado sobre este particular, y hemos tomado algunas ideas para determinar cuál es la naturaleza jurídica de la institución analizada.

Margaret Moses señala que el arbitraje es un sistema privado de juzgamiento, el cual se activa porque las partes han decidido resolver sus disputas fuera del sistema judicial. Generalmente, el arbitraje implica una decisión final y vinculante. El o los árbitros son escogidos por las partes, y puede el proceso ser administrado por una entidad o independiente. Las partes determinan el lugar, legislación aplicable y reglas del procedimiento. En conclusión, el arbitraje es un mecanismo que brinda a las partes sustancial autonomía y control sobre cómo su disputa será resuelta ${ }^{10}$.

El profesor Francisco GonzÁlez de Cossío recoge el criterio de Charles JARROSON, y señala que el arbitraje es una institución por la cual un

University of Illinois Law Review 695, 2001, disponible en http://heinonline.org/HOL/LandingPage?handle=hein.journals/unilllr2001\&div=31\&id=\&page=

9. No es materia de este artículo discutir si el arbitraje es un contrato o el ejercicio de la potestad jurisdiccional, ya que ha quedado claro en un inicio que la segunda es la teoría aceptada por el autor de este ensayo. Sin embargo, tal distinción es intrascendente para el objeto de este artículo, porque si el arbitraje es un contrato, más sencillo aún resulta la aplicación de una modificación a las etapas del proceso.

10. M. Moses, Introduction to International Commercial Arbitration, Loyola University Chicago School of Law, Public Law and Legal Theory Research Paper No. 2011-027, 2011, disponible en http://papers.ssrn. com/sol3/papers.cfm?abstract_id=1942525. 
tercero resuelve una diferencia que divide a dos o más partes, en ejercicio de la función jurisdiccional que le ha sido confiada por ellos ${ }^{11}$. En este mismo texto, el autor señala que no son arbitraje la mediación y conciliación (por las facultades del tercero en la disputa), mandato (por la falta de posibilidad de encomendar al árbitro cómo resolver), transacción (por la falta de tercero, presencia de concesiones mutuas ausentes en el arbitraje y porque ésta es un contrato, a diferencia del resultado de un contrato) y experto (carencia de juzgador, de problema jurídico y de obligatoriedad de la decisión); y explica por descarte los elementos que vuelven al arbitraje una institución jurídica única $^{12}$.

Juan Guillermo LoHMAnN señala que el arbitraje es "la institución que regula el acuerdo de voluntades por el cual dos o más partes deciden someterse a uno o más terceros, que aceptan el encargo, para la solución de un cierto conflicto en Derecho Privado respecto del cual dichas partes tienen capacidad de disposición, obligándose previamente a no llevar la controversia a tribunales ordinarios sin el previo fallo arbitral, el cual deberá expedirse con arreglo a ciertas formalidades"13.

Múltiples otras definiciones y descripciones, tanto del sistema anglosajón como del romano germánico del derecho, concuerdan con las antes transcritas, y no es menester mencionarlas ${ }^{14}$. De lo expuesto, se desprende que más allá de que el arbitraje sea tratado como el ejercicio de una función jurisdiccional derivada, como un contrato o como una figura mixta, tiene elementos que lo distinguen de otras instituciones.

11. C. Jarrosson, La notion d'arbitrage, droit et de jurisprudence, Bibliothèque de Droit Privé, Librairie Generale, París, 1987, p. 372, en F. González De Cossío, Sobre la Naturaleza Jurídica del Arbitraje, Homenaje a Don Raúl Medina Mora, Colección Foro de la Barra Mexicana, Themis, México D.F., 2008, p.3, disponible

12. Ibídem, p. 8 .

13. J. Guillermo LuCA, El Arbitraje, Biblioteca "Para Leer el Código Civil", Fondo Editorial de la Pontificia Universidad Católica del Perú, Lima, 1987, volumen 5, p. 39.

14. La jurisprudencia nacional se adhiere a las definiciones antes descritas. Ver Resolución S/N Colonial Compañía de Seguros y Reajustes S.A. vs. La Ganga RCA Cía. Ltda., Año CII, Serie XVII, Gaceta Judicial 7, p. 1909 de 10 de octubre de 2011. 
i) Un listado de dichos elementos podría ser:

- Institución jurídica que genera un sistema privado de resolución de controversias.

- Existencia de un tercero, que decide sobre la controversia presentada.

- Posibilidad de disponer de los derechos en conflicto (materia tranigible).

- Las partes tienen amplia capacidad de determinar las características del proceso (árbitros, idioma, confidencialidad, sede, reglas, administración), pero no pueden regular su resultado.

- La resolución es de carácter vinculante para las partes.

- No existe intervención de la justicia ordinaria en el proceso de generación del laudo, sino solamente para revisar la aplicación del proceso (acción de nulidad) o para su ejecución.

En la lista antes elaborada se distingue que si el procedimiento se tramite completamente de manera externa a los órganos de administración de justicia estatales, este cumple con uno de los requisitos esenciales para ser considerado arbitraje. Es por esto que el objeto de este ensayo no se trata de proponer la subsunción del arbitraje al control judicial, sino proveer mecanismos de control al arbitraje dentro de sí mismo.

\subsection{Razones que fundamentan la necesidad de segunda instancia o apelación en arbitraje}

Dado que la obligación de confidencialidad del proceso arbitral ha sido aplicada de manera distorsionada en nuestro medio (confundiendo la reserva que debe existir sobre las partes involucradas y la materia del proceso, con un sigilo sobre el contenido de los laudos), existien pocas publicaciones de laudos arbitrales, el conocimiento de los mismos y su calidad llega a los abogados a través de la propia práctica profesional, o en menor medida por la vía académica.

Sin embargo, de los múltiples laudos que he debido revisar por mi ejercicio como abogado y asesor de entidades privadas, principalmente, he llegado a la conclusión que los árbitros y el contenido de sus decisiones 
no tienen control alguno sobre su contenido, al menos en comparación con los jueces ordinarios. Baso mi afirmación en lo siguiente:

a) A diferencia de los jueces, ninguna norma de carácter legal regula los deberes y responsabilidades de los árbitros respecto al proceso que conocen. No me refiero a las regulaciones específicas de los centros arbitrales (que por cierto regulan una porción, mas no la totalidad, de los arbitrajes que se tramitan), sino a normas que impliquen que las partes puedan demandar sanción o algún tipo de resarcimiento en caso de evidente error en el laudo o perjuicio por el mismo.

Resulta peculiar esta situación, ya que el Código Orgánico de la Función Judicial expresamente declara que los árbitros ejercen función jurisdiccional. Cabe entonces preguntarse, ¿por qué razón no se sujetan, en lo aplicable, a los deberes y obligaciones de los jueces? No encuentro justificación a tal exoneración, tanto más que inclusive los órganos auxiliares de administración de justicia tienen claramente establecidas sus obligaciones en la ley ${ }^{15}$.

Basta observar la legislación colombiana para obtener una muestra de que los árbitros en efecto pueden someterse a control de sus actuaciones, tanto más que ejercen una función que podríamos denominar "pública temporal". El Código Disciplinario Único, que rige el régimen de control y sanción de todos los funcionarios públicos de la República de Colombia, establece en su artículo 55 parágrafo segundo, que:

Los árbitros y conciliadores quedarán sometidos además al régimen de faltas, deberes, prohibiciones, inhabilidades, incompatibilidades, impedimentos y conflictos de intereses de los funcionarios judiciales en lo que sea compatible con su naturaleza particular. Las sanciones a imponer serán las consagradas para los funcionarios judiciales acorde con la jerarquía de la función que le competía al juez o magistrado desplazado.

15. Ver artículos 128, 129 y 130 del Código Orgánico de la Función Judicial para revisar en detalle los deberes de los jueces. 
El establecer un sistema de control adecuado resulta especialmente necesario porque no hay organismo a cargo de responder por el error arbitral, a diferencia de lo que ocurre con el error judicial. El artículo 11 de la Constitución ecuatoriana vigente señala:

Art. 11.- EI ejercicio de los derechos se regirá por los siguientes principios:

9. El más alto deber del Estado consiste en respetar y hacer respetar los derechos garantizados en la Constitución.

El Estado, sus delegatarios, concesionarios y toda persona que actúe en ejercicio de una potestad pública, estarán obligados a reparar las violaciones a los derechos de los particulares por la falta o deficiencia en la prestación de los servicios públicos, o por las acciones u omisiones de sus funcionarias y funcionarios, y empleadas y empleados públicos en el desempeño de sus cargos.

El Estado ejercerá de forma inmediata el derecho de repetición en contra de las personas responsables del daño producido, sin perjuicio de las responsabilidades civiles, penales y administrativas.

El Estado será responsable por detención arbitraria, error judicial, retardo injustificado o inadecuada administración de justicia, violación del derecho a la tutela judicial efectiva, y por las violaciones de los principios y reglas del debido proceso.

Cuando una sentencia condenatoria sea reformada o revocada, el Estado reparará a la persona que haya sufrido pena como resultado de tal sentencia y, declarada la responsabilidad por tales actos de servidoras o servidores públicos, administrativos o judiciales, se repetirá en contra de ellos. (El énfasis me corresponden).

Como hemos visto, esta norma no le es aplicable a los árbitros, a diferencia de lo que ocurre en otros países. Entonces, si no existe control de la decisión dentro del proceso y los árbitros están exentos de sanción por su error, nos encontramos en un caso en el que una persona que ejerce un 
deber constitucionalmente conferido no es responsable por el desarrollo de su función, lo cual es inadmisible en un Estado de Derecho.

b) La acción de nulidad en contra del laudo arbitral no es cura para el problema señalado. Esto debido a la limitación que la Ley de Arbitraje y Mediación vigente ${ }^{16}$ establece en su artículo 31:

Art. 31.- Cualquiera de las partes podrá intentar la acción de nulidad de un laudo arbitral, cuando:

a) No se haya citado legalmente con la demanda y el juicio se ha seguido y terminado en rebeldía. Será preciso que la falta de citación haya impedido que el demandado deduzca sus excepciones o haga valer sus derechos y, además, que el demandado reclame por tal omisión al tiempo de intervenir en la controversia;

b) No se haya notificado a una de las partes con las providencias del tribunal y este hecho impida o limite el derecho de defensa de la parte;

c) Cuando no se hubiere convocado, no se hubiere notificado la convocatoria, o luego de convocada no se hubiere practicado las pruebas, a pesar de la existencia de hechos que deban justificarse;

d) El laudo se refiera a cuestiones no sometidas al arbitraje o conceda más allá de lo reclamado; o,

e) Cuando se hayan violado los procedimientos previstos por esta Ley o por las partes para designar árbitros o constituir el tribunal arbitral.

Es claro que el arbitraje no ha sido diseñado para tener control judicial de contenidos, posición con la que manifiesto mi absoluto acuerdo. Es así que la acción de nulidad prevista en la ley vigente hace relación a vicios

16. Codificación de la Ley de Arbitraje y Mediación, Registro Oficial No. 417 de 14 de diciembre de 2006. 
del proceso arbitral, que son el único espacio que se abre para que la justicia ordinaria observe lo que ha ocurrido dentro de un procedimiento por naturaleza privado y confidencial.

En caso de determinarse un error procesal, el Presidente de la Corte Provincial respectiva ordenará se reponga el proceso al momento anterior a la nulidad, para que una vez subsanada, se continúe con el aquel. Claramente el control no se extiende, ni puede extenderse, al contenido material del laudo.

c) Más allá del proceso de selección de árbitros, regulado actualmente por los distintos centros de arbitraje y mediación en el país y a nivel internacional, que se lleva (o debería llevarse) a cabo de antes de su inclusión como tales en las listas respectivas, no existe control previo respecto al conocimiento y demás cualidades personales que son parte del individuo a quien le será confiado el conocimiento de un caso, y conforme se ha dicho previamente, el ejercicio de una potestad pública de manera temporal.

Tradicionalmente, se han endilgado múltiples defectos a la administración de justicia ordinaria. Uno de ellos, talvez el más importante desde la situación actual de varios países de América Latina, es la influencia de la política en la justicia, o dicho de manera más general, la existencia de influencia externa en las decisiones judiciales. Citando a Roberto GARGARELLA, quien se refiere a la situación argentina, pero que es perfectamente aplicable a otros países:

Los intentos de los poderes políticos a fin de contar con un poder judicial sumiso pueden verificarse aun en países de larga tradición jurídica, pero se tornan más evidentes y más violentos en países jurídicamente menos asentados. En la Argentina, por ejemplo, es una situación típica que cada nuevo gobierno pretenda quitar «independencia» a la Corte, nombrando otra completamente nueva, o cambiando, al menos, a los jueces que sean necesarios para llegar a contar con una mayoría favorable $^{17}$.

17. R. Gargarella, La Justicia frente al Gobierno, Serie Pensamiento Jurídico Contemporáneo. No. 3, Corte 
Otro problema que ha sido materia de importante análisis y esfuerzos por parte del área administrativa de la función judicial es la corrupción, mal que aqueja a múltiples oficinas y encargados de administrar justicia a nivel mundial. Los autores señalan que existe "amplio consenso en considerar a la corrupción grave y extendido" de varios sistemas judiciales, y lo señalan como relevante porque "la prevalencia de la corrupción en un sistema judicial destruye los componentes esenciales de su legitimidad y credibilidad, tales como la imparcialidad, previsibilidad, transparencia y la propia justicia de su actuación y resoluciones"18.

Un tercer problema, detectado en la práctica profesional, que es poco descrito en la doctrina nacional o internacional, es el simple y llano desconocimiento de las normas o derecho por parte de los jueces. A pesar de los esfuerzos que realizan las entidades públicas por revertir esta tendencia, la falta de obligatoriedad de la capacitación continua de los abogados y jueces (cuya omisión lleva a la pérdida de licencia profesional en otras jurisdicciones) hace que la calidad jurídica de los profesionales en derecho dependa exclusivamente de su voluntad e interés por mantener un nivel académico aceptable de cada uno de ellos.

Es ahora pertinente preguntarse: ¿Por qué los defectos antes señalados deben remitirse únicamente al foro judicial y no podrían haber también afectado al foro arbitral? Al no ser este último un cuerpo colegiado dicha afirmación jamás podría ser realizada de manera genérica, sin embargo es necesario señalar que al igual que en casos individuales con los jueces, podrían existir árbitros sujetos a cualesquiera de las críticas señaladas en esta sección ${ }^{19}$. Con relación al último problema planteado, esto es el desconocimiento de la materia jurídica puesta en su conocimiento, cabe señalar

Constitucional para el Período de Transición, primera reimpresión, Quito, 2011, p. 247. El análisis del profesor Gargarella se extiende respecto a distintas formas de falta de independencia judicial (poderes políticos, clamor popular, estructura judicial y burocracia interna), que probablemente no son relevantes para el artículo, pero resultan reveladoras para el análisis de la independencia judicial.

18. F. Eguiguren Praeli, ¿Qué hacer con el sistema judicial?, Agenda Perú, Lima, 1999, p. 56.

19. Se han efectuado estudios que revelan que los árbitros tienden a resolver los casos sometidos a su conocimiento en razón de sus antecedentes profesionales. Para explorar el asunto a profundidad, ver J. CHOI, J. E. FISCH y A. PRITCHARD, The Influence of Arbitrator Background and Representation on Arbitration Outcomes, New York University School of Law, Center for Law, Economics and Organization, Law \& Economics Research Paper Series, Working Paper 12-17, September 2013, disponible en http://papers.ssrn. com/sol3/papers.cfm?abstract_id=2109712. 
que el problema podría ser aún más profundo en materia arbitral que judicial, ya que en la mayoría de los casos el ejercicio del arbitraje es una actividad secundaria dentro de la práctica profesional de los abogados que tienen tal calidad. Por lo tanto, el tiempo que efectivamente puede ser destinado a su función de juez es mucho menor que la de un juez ordinario, lo cual aumenta las posibilidades de error.

Todos estos defectos generan imposibilidad de predecir las decisiones, sean estas judiciales o arbitrales, lo cual crea incertidumbre y comportamientos erráticos en los actores jurídicos del medio ${ }^{20}$.

d) El problema respecto a la falta de control de los árbitros no es una materia que concierne únicamente al arbitraje comercial, sino que ha sido una situación ampliamente comentada en el arbitraje de inversión durante los últimos años. En dicha área se ha sostenido principalmente a nivel político que los árbitros tienden a favorecer a ciertas naciones o inversionistas ${ }^{21}$, y se han considerado varias opciones para solucionar tal problema, tales como la instauración de apelación en los arbitrajes estado-inversionista, la creación de una sala de la Corte Internacional de Justicia para atender este tipo de casos, entre otras ideas ${ }^{22}$.

Finalmente, respecto al arbitraje se han generado comportamientos judiciales inesperados, que podrían de alguna forma reflejar la falta de confianza que produce en el sistema la carencia de control sobre el contenido de los laudos. En un estudio elaborado en el año 2004, se ha determinado que los jueces norteamericanos estatales, quienes están facultados para controlar la validez de los contratos, entre otros las cláusulas arbitrales, tienen mucha mayor tendencia a declarar la invalidez de tales convenios

20. A. NiBLETT, Tracking Inconsistent Judicial Behavior, University of Toronto Faculty of Law, 2012, disponible en http://papers.ssrn.com/sol3/papers.cfm?abstract_id=1434685.

21. S. D. FRANCK, Development and Outcomes of International Treaty Arbitration, Harvard International Law Journal, Vol. 50, No. 2, 2009, p. 448 y siguientes, disponible en http://papers.ssrn.com/sol3/papers.cfm?abstract_id=1406714. Cumplo con advertir que esta posición, e incluso la validez científica del reporte antes citado, han sido cuestionados por otros autores. Ver: Fairness and independence in investment arbitration: A critique of Susan Franck's «Development and Outcomes of Investment Treaty Arbitration», G. VAN HARTEN, ITN Quarterly 2010, disponible en http://papers.ssrn.com/sol3/papers.cfm?abstract_id=1740031.

22. Arbitration and Judicialization, Alec Stone Sweet, Oñati Social-Legal Series, Vol. 1, No. 9, 2011 - Autonomy and Heteronomy of the Judiciary in Europe, Guipuzkoa, España, p.15, disponible en http://papers.ssrn. com/sol3/papers.cfm?abstract_id=1988923. and Heteronomy of the Judiciary in Europe, Guipuzkoa, España, p.15, disponible en http://papers.ssrn.com/sol3/papers.cfm?abstract_id=1988923. 
por sobre otros contratos, y por ende obligar a las partes a acudir a las cortes estatales o federales ${ }^{23}$. Esta declaratoria de invalidez se fundamenta especialmente en la teoría del abuso del derecho, que se plasma en cláusulas arbitrales que a criterio de los jueces son tan injustas o tan inclinadas hacia una parte, que son contrarias a la "buena conciencia" o buena fe.

Las razones expresadas en esta sección se plantean como cuestionamientos pertinentes a la falta de control del contenido de los laudos arbitrales, y que podrían ser todas ellas atendidas, total o parcialmente, con la existencia de segunda instancia o apelación dentro de la sede arbitral.

\section{2. ¿La ley ecuatoriana permite la realización de segunda instancia o apelación en arbitraje?}

La apelación tiene funciones muy importantes en el derecho. En primer lugar, provee a la parte perdedora en primera instancia de una oportunidad de defender sus intereses ante lo que considera una sentencia errónea. Adicionalmente, sirve para alcanzar certeza jurídica y coherencia doctrinal y jurisprudencial, partiendo de la asunción de que la revisión del superior aumenta la consistencia de las decisiones de la primera instan$\mathrm{cia}^{24}$.

Es remarcable que la ley ecuatoriana no indica el contenido preciso del convenio arbitral, sino que solamente lo define y señala su objetivo (artículo 5 LAM), por lo cual deja por las partes y a las regulaciones secundarias de los centros de arbitraje determinen el contenido "ideal" de dicho acuerdo privado que las partes incluyen en los contratos o celebran por cuerda separada.

Vistos los problemas que pueden suscitarse de la falta de control, así como las virtudes de la apelación, cabe preguntarse si la ley ecuatoriana con-

23. S. RANDALL, Judicial Attitudes Toward Arbitration and the Resurgence of Unconscionability, The University of Alabama School of Law, Buffalo Law Review, Vol. 52, 2004, disponible en http://papers.ssrn.com/sol3/ papers.cfm?abstract_id=663982.

24. Ibídem, 22. 
tiene algún impedimento para que este mecanismo sea establecido en las cláusulas de convenio arbitral. Creemos necesario, dada la generalidad del resto de la ley, concentrar la discusión en el artículo 30 de la misma:

Los laudos arbitrales dictados por los tribunales de arbitraje son inapelables, pero podrán aclararse o ampliarse a petición de parte, antes de que el laudo se ejecutoríe, en el término de tres días después de que ha sido notificado a las partes. Dentro de este mismo término los árbitros podrán corregir errores numéricos, de cálculo, tipográficos o de naturaleza similar. Las peticiones presentadas conforme a lo establecido en este artículo serán resueltas en el término de diez días contados a partir de su presentación.

Los laudos arbitrales no serán susceptibles de ningún otro recurso que no establezca la presente Ley. (El énfasis me corresponde)

Vista la disposición referida, cabe preguntarse si es que la apelación que está expresamente prohibida en la Ley de Arbitraje y Mediación se refiere a la posibilidad de revisar el caso en sede arbitral, o únicamente busca impedir que el laudo arbitral sea objeto de revisión judicial. Dada la epoca de la redacción de la disposición, la segunda opción es la probable ${ }^{25}$.

Para sostener esta disposición, cabe analizar desde la perspectiva doctrinaria qué es un recurso, para identificar si el actual texto de la ley permitiría la apelación o segunda instancia en sede arbitral, o se requeriría una reforma legal que elimine la prohibición antes señalada ${ }^{26}$.

Eduardo Devis Echandía indica que por "recurso" se entiende la petición formulada por una de las partes, principales o secundarias, para que el mismo juez que profirió una providencia o su superior la revise, con el fin de corregir los errores de juicio o de procedimiento (in judicando o in procedendo) que en ella se hayan cometido ${ }^{27}$. (El énfasis me corresponde).

25. La disposición transcrita forma parte de la Ley de Arbitraje y Mediación original, publicada en Registro Oficial No. 145 de 4 de septiembre de 1997. A tal fecha, ninguna de las iniciativas internacionales respecto a apelación en arbitraje había sido desarrollada, como se verá más adelante.

26. Es inútil para el análisis revisar la legislación procesal civil, supletoria en materia arbitral, ya que la misma se refiere a recursos judiciales, específicamente.

27. E. Devis ECHANDÍA, Teoría General del Proceso, Editorial Universidad, Buenos Aires, 1997, p. 505. 
Jaime Flor RUBIANES recoge dos definiciones sobre recurso que sirven para el análisis en proceso. Cita Flor Rubianes a Lino Enrique Palacio, que define al recurso como "Acto procesal en cuya virtud la parte que se considera agraviada por una resolución judicial pide su reforma o anulación, total o parcial, sea el mismo Juez o Tribunal que la dictó o a un Juez o Tribunal jerárquicamente superior". Eduardo J. Couture, citado también por Flor RUBIANES, indica que "Los recursos son, genéricamente hablando, medios de impugnación de los actos procesales. Realizado el acto, la parte agraviada por él tiene, dentro de los límites que la ley le confiere, poderes de impugnación destinados a promover la revisión del acto y su eventual modificación" 28 .

Parecería que las definiciones señaladas indican que la definición de recurso implica necesariamente la existencia de un proceso judicial. Sin embargo de ello, debo admitir que existen otras normas legales en nuestro sistema jurídico, no judiciales, que también hacen referencia a recursos, principalmente en sede administrativa, situación que podría contradecir el argumento anterior.

Más allá de lo dicho, como se verá más adelante, las reglas existentes en otras legislaciones relativas a apelación en arbitraje no enfocan este paso procesal como una instancia superior, sino como un procedimiento autónomo de revisión del laudo arbitral en sede judicial ${ }^{29}$, por lo que su implementación no implicaría violación a la ley ecuatoriana vigente, en el supuesto que los recursos prohibidos por la Ley de Arbitraje y Mediación no sean únicamente los judiciales.

\subsection{Aplicación de cláusulas de segunda instacia en arbitraje}

Con el objetivo de no extender innecesariamente el ensayo, me remito a los ejemplos a mano sobre la aplicación de apelación dentro de sede arbitral. Es necesario señalar que esta tendencia es una clara minoría en la legislación internacional. Por ejemplo, las leyes arbitrales de Colombia, España y Chile siguen señalando que el arbitraje tendrá solamente revisión judicial limitada.

28 J. Flor Rubianes, Teoría General de los Recursos Procesales, Librería Jurídica Cevallos, Quito, 2002, p. 15.

29. Ver http://go.adr.org/AppellateRules 
La Ley No. 19.971 de Chile señala que:

Art. 34.- La petición de nulidad como único recurso contra un laudo arbitral.

[1] Contra un laudo arbitral sólo podrá recurrirse ante un tribunal mediante una petición de nulidad conforme a los numerales [2] y [3] de este artículo.[...] $]^{30}$.

La Ley No. 1562 de 2012 de Colombia indica dos medios de impugnación en sede judicial para el laudo arbitral:

Artículo 40. Recurso extraordinario de anulación. Contra el laudo arbitral procede el recurso extraordinario de anulación, que deberá interponerse debidamente sustentado, ante el tribunal arbitral, con indicación de las causales invocadas, dentro de los treinta (30) días siguientes a su notificación o la de la providencia que resuelva sobre su aclaración, corrección o adición. Por secretaría del tribunal se correrá traslado a la otra parte por quince (15) días sin necesidad de auto que lo ordene. Vencido aquel, dentro de los cinco (5) días siguientes, el secretario del tribunal enviará los escritos presentados junto con el expediente a la autoridad judicial competente para conocer del recurso.

Artículo 45. Recurso de revisión. Tanto el laudo como la sentencia que resuelva sobre su anulación, son susceptibles del recurso extraordinario de revisión por las causales y mediante el trámite señalado en el Código de Procedimiento Civil. Sin embargo, quien tuvo oportunidad de interponer el recurso de anulación no podrá alegar indebida representación o falta de notificación. Cuando prospere el recurso de revisión, la autoridad judicial dictará la sentencia que en derecho corresponda ${ }^{31}$.

30. Ley No. 19.971 sobre Arbitraje Comercial Internacional, publicada el 29 de enero de 2004, disponible en http://www.leychile.cl/Navegar?idNorma=230697

31. Estatuto de Arbitraje Nacional e Internacional, Ley No. 1563 de 2012, publicada en el Diario Oficial No. 48.489de 12 de julio de 2012 . 
Por su parte, la ley de Arbitraje, No. 60/2003 de 23 de diciembre de 2013, reformada por Ley No. 11/2011 de 20 de mayo de 2011, señala que:

\begin{abstract}
Artículo 43. Cosa juzgada y revisión de laudos. El laudo produce efectos de cosa juzgada y frente a él sólo cabrá ejercitar la acción de anulación y, en su caso, solicitar la revisión conforme a lo establecido en la Ley 1/2000, de 7 de enero, de Enjuiciamiento Civil para las sentencias firmes ${ }^{32}$.
\end{abstract}

Sin embargo de la existencia de estas normas, que parecerían limitar el acceso a recursos incluso en sede arbitral, por no estar previstos expresamente en la ley, cabe recalcar que varios centros de arbitraje de estos países han entendido que al ser el convenio arbitral un acuerdo de voluntad que regula enteramente la controversia, bien puede establecerse apelación sin violar la ley (asumiendo también como válidas las afirmaciones de las sección previa de este ensayo).

Por ejemplo, la Corte Española de Arbitraje acoge abiertamente la posibilidad de una segunda instancia arbitral, para lo cual ha creado un procedimiento que consta en su Reglamento de Funcionamiento ${ }^{33}$, y ha propuesto, además, un sencillo modelo de cláusula arbitral con provisión de apelación ${ }^{34}$. Debo expresar que el procedimiento propuesto por este centro arbitral no me resulta atractivo, ya que lamentablemente prevé la existencia de período de prueba así como múltiples actuaciones de las partes, lo que podría causar la pérdida de la característica de celeridad, esencial en el arbitraje tal como lo hemos señalado en secciones previas ${ }^{35}$.

32. Ley de Arbitraje, No. 60/2003 reformada, publicadas sus reformas en el Boletín Oficial del Estado No. 121 de 21 de mayo de 201.

33. Ver http://corteespanolaarbitraje.es/wp-content/uploads/2014/05/articulo-39-segunda-instancia-arbitral1.pdf.

34. "Toda controversia que se derive del presente contrato o de un acuerdo, se resolverá definitivamente mediante arbitraje administrado por la Corte Española de Arbitraje, de acuerdo con su Reglamento y Estatuto, a la que se encomienda la administración del arbitraje y el nombramiento del árbitro o de los árbitros. Las partes se otogan el derecho de apelar el laudo o laudos que se dicten ante un tribunal arbitral de segunda instancia, con carácter previo a la eventual incoación de la acción de anulación, de conformidad con lo previsto en el reglamento de la Corte Española de Arbitraje". Ver http://corteespanolaarbitraje.es/wp-content/uploads/2014/05/convenio-arbitral-prevision-de-segunda-instancia.pdf.

35. Existen múltiples casos adicionales que podrían ser citados, como el del Centro de Arbitraje y Mediación de la Cámara de Comercio de Santiago de Chile. Ver artículo 40 del Reglamento Procesal de Arbitraje, disponible en http://www.camsantiago.cl/reglamento_arbitraje_nacional.html. 
De alguna manera, podría pensarse que el modelo norteamericano se parece a lo antes indicado respecto al español o chileno. Esto por cuanto la Ley Federal de Arbitraje (Federal Arbitration Act) ${ }^{36}$ no prevé tampoco ningún recurso dentro de la sede arbitral, sino la posibilidad limitada de anulación de los laudos arbitrales por parte de las cortes federales o estatales. Sin perjuicio de ello, la práctica de segunda instancia en arbitraje es relativamente común comparada con el derecho romano germánico, especialmente por cuanto las partes de litigios complejos y sus abogados no se sienten cómodos (con toda justificación) teniendo "un solo disparo" en el arbitraje, y buscan que exista cierto nivel de control de las decisiones, especialmente en casos de alta cuantía económica

Dada esta práctica, la Asociación Americana de Arbitraje (en adelante AAA) expidió con fecha efectiva 1 de noviembre de 2013, un modelo de reglas de apelación de laudos arbitrales, a las que las partes que escogen los servicios de tal centro pueden adherirse ${ }^{37}$. Las reglas son bastante menos complejas que las españolas referidas previamente, lo que refleja una vez más la adaptabilidad, flexibilidad y practicidad del modelo de derecho de la escuela del common law.

Debe mencionarse también en este acápite a las reglas de apelación en arbitraje de JAMS, organización que brinda servicios para resolución de controversias en Estados Unidos de América, quienes propusieron a sus usuarios reglas de apelación de laudos arbitrales en junio de $2003^{38}$.

Finalmente, y como ejemplo destacado en la legislación de la región debe señalarse el caso peruano, que incluye normativa clara y efectiva sobre la apelación. La Ley General de Arbitraje No. 26572 de 20 de diciembre de $1995^{39}$ incluye expresamente la facultad de las partes litigantes en arbitraje de impugnar la resolución en apelación arbitral.

El artículo 60 de la Ley General de Arbitraje señala que los laudos pueden ser impugnados por apelación ante la sede judicial, o ante una segunda instancia arbitral. Esta última forma de impugnación procederá con

36. Título 9, US Code, Sección 1-14, disponible en https://www.aaau.org/media/5045/federal\%20arbitration\%20act.pdf.

37. Ver https://www.adr.org/aaa/ShowProperty?nodeId=/UCM/ADRSTAGE2016218.

38. Ver http://www.jamsadr.com/appeal/.

39. Publicada el 3 de enero de 1996. 
acuerdo expreso de las partes, o en caso de silencio de la cláusula respecto a la interposición de recursos.

Las reglas de la apelación son claras y prevén un procedimiento expedito para conseguir un laudo final: el tribunal de apelación se conformará de la misma forma que el tribunal inicial, se recibirán exposiciones de las partes respecto al recurso y se otorgará un término para resolver, sin admitir medio probatorio alguno.

\section{3. ¿Cómo debe incorporarse tal disposición en la cláusula estándar ecuatoriana?}

Como ha quedado visto de la experiencia internacional, aun cuando la ley parece impedir el acceso a recursos ulteriores, este existe y se aplica, habiendo tenido ya considerable análisis en otras jurisdicciones. Sin embargo, existen dos modalidades que podrían aplicarse. La primera implica incluir las reglas de la apelación al convenio arbitral, tal como lo sugiere la AAA; y en la segunda se delega el procedimiento de apelación al reglamento del respectivo centro de arbitraje, opción que eventualmente es más sencilla para las partes, pero implica pérdida de control del trámite de este recurso arbitral.

Sea que se incluya en la cláusula misma o en los reglamentos de los centros arbitrales, creemos que los siguientes pueden ser criterios básicos para construir tales reglas de tal manera que esta segunda instancia funcione adecuadamente:

a) La apelación requiere expreso acuerdo de las partes, como cualquier otra acción en la materia.

b) Al ser apelado un laudo, este no podrá ser ejecutado ni podrá ser objeto de acción de nulidad judicial.

c) Esta impugnación debe permitirse por errores relevantes de derecho o apreciación de los hechos claramente errónea, que la parte perjudicada determine expresamente. 
d) Para agilidad en su aplicación, el recurso debería tramitarse a través de un Centro de Arbitraje.

f) La selección de los miembros del tribunal arbitral de alzada debe ser realizada directamente por el Centro de Arbitraje que administra el proceso, por sorteo de su lista, salvo determinación expresa de los árbitros a considerar.

g) El recurso debe ser fundamentado, y el tribunal Arbitral de alzada debe tener la posibilidad de calificar su procedencia.

h) El tribunal arbitral de alzada podrá calificar su propia competencia, pero no la competencia del tribunal inferior. Si se declara incompetente, el laudo original deberá mantenerse.

i) Más allá del recurso de apelación y su contestación, y eventualmente la realización de una audiencia, el tribunal arbitral de alzada deberá expedir su laudo en virtud de los méritos del proceso.

j) Debe establecerse un tiempo límite para la expedición del laudo.

k) El tribunal arbitral de alzada podrá expedir su propio laudo, modificar el del tribunal inferior, pero no podrá enviar el proceso al tribunal inferior para que este dicte un nuevo laudo.

\section{Conclusión}

A lo largo del texto se ha presentado claramente la postura de este ensayo, y es tratar de incentivar el debate en el foro jurídico nacional y regional sobre la posibilidad de contar con un control del contenido de los laudos arbitrales, dentro de la propia jurisdicción arbitral, por lo que no es necesario extenderse en conclusiones repetitivas. Creemos de manera sincera que está en manos de los distintos Centros de Arbitraje nacionales determinar reglas de apelación y ponerlas a disposición de las partes interesadas, de tal manera que la práctica de la revisión y control de los laudos arbitrales se popularice en el medio jurídico. 
La sugerencia de implementar apelación en arbitraje es presentada con el afán de preservar y consolidar el arbitraje como un método de solución de controversias válido y confiable, al que las partes puedan acudir sin reservas o temor por la falta de control que se evidencia en ciertos laudos. No constituye esta exposición el resultado de crítica a un laudo o actuación específico, ya que de ser ese el caso, se mencionaría tal laudo sin reserva alguna, más allá de las impuestas por la norma.

Considero sinceramente que en caso que el arbitraje continúe teniendo episodios en que los laudos son abiertamente arbitrarios (lo cual ocurrirá en el futuro sin duda, por lo explicado en el texto), y si las partes continúen sin contar con mecanismos de control efectivos para el ejercicio de esta potestad pública, el arbitraje corre el riesgo de perder su bien ganada reputación, o de ser objeto de excesivo e indebido control estatal, lo cual distorsionaría sin remedio esta institución del derecho.

Otra alternativa, que debe ser materia de análisis en otro ensayo, es la determinación a nivel regulatorio de requisitos para acceder a la calidad de árbitro, como ha ocurrido en otros países ${ }^{40}$, para así limitar especialmente la actuación en casos de conflictos de interés que también se presentan en nuestro medio; pero hay que reconocer que tal acción no solucionaría todos los problemas que el control mediante apelación sí atiende.

40. Ibídem, 21, p. 7 y siguientes. 